\title{
Drug pricing apps only as effective as incentives to use them
}

\author{
n Cite as: CMAJ 2019 October 15;191:E1143-4. doi: 10.1503/cmaj.1095800
}

Posted on cmajnews.com on Sept. 25, 2019

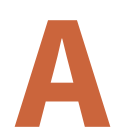

pplications that nudge doctors to prescribe more affordable medicines are popping up in Canada and the United States. But experts say these apps are unlikely to change prescribing practices unless doctors have the right incentives to use them.

Drug pricing apps need physician buyin to work, said Dr. Iris Gorfinkel, a Toronto physician and advocate for drug pricing transparency. In the United Kingdom, for example, physician groups have a pool of money to spend on patients, including on medicines, and they are held accountable by other prescribers in their group if they overspend.

Other incentives may include rewarding physicians for using drug pricing apps or tapping into their competitive spirit by comparing their prescribing practices to peers.

According to Gorfinkel, apps that encourage cost-effective prescribing have been slow to catch on in the US because doctors lack these kinds of incentives.

How apps are designed to nudge doctors can also make or break their success, she said. "If there's too much information, the doctor tunes out." Nudges make sense when there is a larger price difference between the options, as in the case of the hypertension drug perindopril, which costs $\$ 95$ for $5 \mathrm{mg}$, compared to ramipril, an alternative that costs $\$ 30$ for $5 \mathrm{mg}$, Gorfinkel explained. But doctors are likely to be turned off by apps that give a long list of alternatives with wide pricing ranges.

Nudges aren't necessary for $90 \%$ to $95 \%$ of drugs that doctors prescribe regularly, said Dr. Darren Larsen, chief medical officer of OntarioMD, an organization funded by the province to support physician adoption of digital health tools. For instance, it's not helpful to flag well-

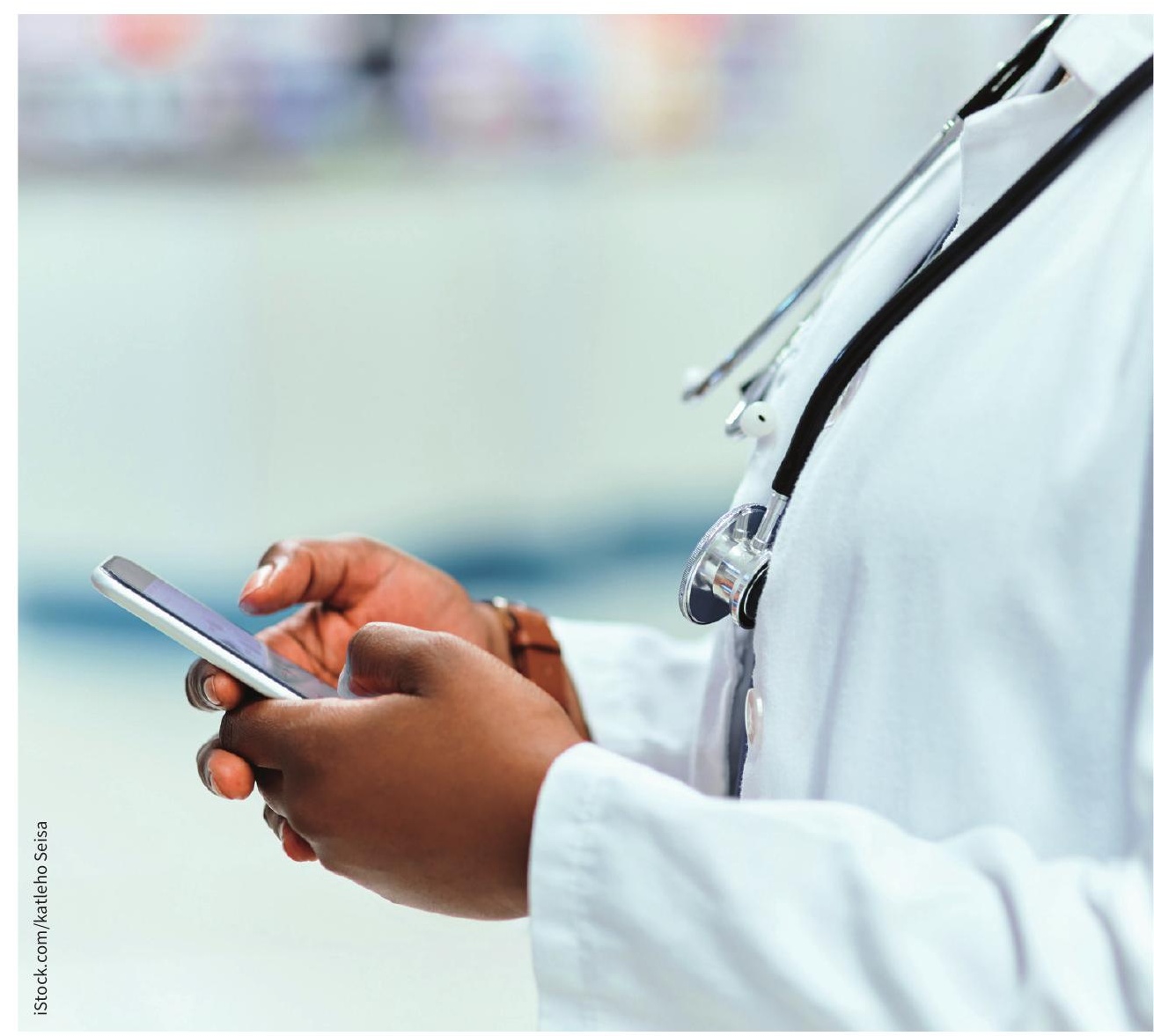

How apps nudge doctors to prescribe cost-effective medicines can make or break their success, experts say.

known generics like amoxicillin for strep throat or metformin for diabetes. "I don't need to be alerted about those medicines if they're a couple of cents off per tablet from another drug."

Nudges should also be subtle, Larsen said. Pop-up alerts can become distracting, and providers may start closing them automatically. Instead, an app might highlight expensive drugs in red and more cost-effective options in green, and let providers click to see alternatives, he sug- gested. "We don't want to impede the workflow of physicians, nurses and nurse practitioners with yet another tick-off box or alert we have to cancel."

An Ontario-wide system that nudges doctors to prescribe cheaper drugs is something that "everybody wants," Larsen said. "The issue is, where does it land on a provincial prioritization list?"

OntarioMD is integrating a digital health drug repository into electronic medical records that will show providers 
at the point of prescribing a full list of the publicly funded and monitored drugs dispensed to a patient. OntarioMD hopes to get approval from the province to add average wholesale pricing information within this repository. But there are no plans yet to nudge physicians to prescribe cost-effective drugs.

In the meantime, private Canadian firms are developing drug pricing apps for employer drug plans. One such tool, Reformulary, is rolling out to 1500 employers by the end of the year.

Private drug plans contain costs by reimbursing cheaper, equally effective "preferred drugs" at $80 \%$ to $100 \%$, and nonpreferred drugs at $20 \%$ to $50 \%$. Patients and pharmacists can use tools like
Reformulary to see if a prescribed drug is on a plan's preferred list. "For people who are taking nonpreferred drugs, typically about $70 \%$ to $80 \%$ of them switch drugs when their plan implements Reformulary," said Helen Stevenson, CEO of the company.

According to Gorfinkel, the challenge of tools like Reformulary is that pricing information isn't available in the patient's electronic medical record, so "patients are not empowered to question what doctors are prescribing."

As such, it's often the pharmacist who calls the prescriber after the fact to see if they can change the prescription to a preferred drug. According to Larsen, that means "another phone call, another fax and another step for the physician and the pharmacist, and patients have to wait for that follow up." OntarioMD is in "exploratory talks" with Reformulary and other companies about integrating pricing information into electronic medical records, he said.

The ideal drug pricing tool, one that is available at the point of prescribing and nudges doctors to prescribe cost-effective options, may be costly to implement. But Gorfinkel said the cost of doing nothing is "far greater." According to her interviews with UK health officials about their experience implementing drug pricing apps, "for every dollar that's invested, anywhere from \$4 to \$6 is saved."

Wendy Glauser, Toronto, Ont. 